\title{
Implications of announced phase II national allocation plans for the EU ETS
}

\author{
Karsten Neuhoff ${ }^{*}$, Markus Åhman², Regina Betz ${ }^{3}$, Johanna Cludius ${ }^{3}$, Federico Ferrario ${ }^{1}$, \\ Kristina Holmgren ${ }^{2}$, Gabriella Pal ${ }^{4}$, Michael Grubb ${ }^{1}$, Felix Matthes ${ }^{5}$, Karoline Rogge ${ }^{6}$, Misato \\ Sato $^{1}$, Joachim Schleich ${ }^{6}$, Jos Sijm ${ }^{7}$, Andreas Tuerk ${ }^{8,9}$, Claudia Kettner ${ }^{8}$, Neil Walker ${ }^{10}$ \\ ${ }^{1}$ University of Cambridge, Faculty of Economics, Austin Robinson Building, Sidgwick Avenue, Cambridge, CB3 9DE, UK \\ ${ }^{2}$ IVL Swedish Environmental Research Institute, Box 210 60, SE 100 31, Stockholm, Sweden \\ ${ }^{3}$ Centre for Energy and Environmental Markets (CEEM), Lecturer School of Economics, University of NSW, Sydney \\ 2052, Australia \\ ${ }^{4}$ Regional Center for Energy Policy Research (REKK), 1093 Budapest, Fövám tér 8, Corvinus University, Budapest, \\ Hungary \\ ${ }^{5}$ Öko-Institut (Institute for Applied Ecology), Büro Berlin, Novalisstr. 10, D-10115, Berlin, Germany \\ ${ }^{6}$ Fraunhofer Institute for Systems and Innovation Research, Breslauer Strasse 48, 76139 Karlsruhe, Germany \\ ${ }^{7}$ Energy Research Centre of the Netherlands (ECN), PO Box 37154, 1030 AD Amsterdam, The Netherlands \\ ${ }^{8}$ Wegener Center for Climate and Global Change, Economics Department, University of Graz, Universitaetsstrasse 15/F4, \\ A-8010 Graz, Austria \\ ${ }^{9}$ Joanneum Research, Steyrergasse 17-19, 25a, 8010 Graz, Austria \\ ${ }^{10}$ University College Dublin, Belfield, Dublin 4, Ireland
}

\begin{abstract}
We quantified the volume of free allowances that different national allocation plans proposed to allocate to existing and new installations, with specific reference to the power sector. Most countries continue to allocate based on historic emissions, contrary to hopes for improved allocation methods, with allocations to installations frequently based on 2005 emission data; this may strengthen the belief in the private sector that emissions in the coming years will influence their subsequent allowance allocation. Allocations to new installations provide high and frequently fuel-differentiated subsidies, risking significant distortions to investment choices. Thus, in addition to supplying a long market in aggregate, proposed allocation plans reveal continuing diverse problems, including perverse incentives. To ensure the effectiveness of the EU ETS in the future, the private sector will need to be shown credible evidence that free allowance allocation will be drastically reduced post-2012, or that these problems will be addressed in some other way.
\end{abstract}

Keywords: Emissions trading; National allocation plans; Comparison; European Member States

* Corresponding author. Tel.: +44-1223-335290; fax: +44-1223-335299

E-mail address: karsten.neuhoff@econ.cam.ac.uk 


\section{Introduction}

The EU Emissions Trading Scheme is designed to cap emissions of energy-intensive industry in Europe. Under the European Directive on Emissions Trading, each Member State is required to state within the proposed national allocation plan (NAP), both the allocation volume of emissions allowances to the covered sectors and the allocation methodology.

Sensible decisions on the allocation volume or 'cap' level by Member States are crucial. Stringent caps create scarcity, which holds the key to both the environmental efficacy of the scheme and good functioning of the $\mathrm{CO}_{2}$ market. Yet, Neuhoff et al. (2006a, this issue) argue that the volume of allowances allocated under the currently proposed NAPs for phase II is too high, by comparing the NAPs with $\mathrm{CO}_{2}$ emissions projection scenarios and the historic trend of emissions extrapolated forward. The analysis by Betz et al. (2006, this issue) also shows that, in many Member States, allocation for phase II is excessive relative to 2005 emissions, historic trends and country-level projections.

The national allocation plans also have to specify how the allowances are distributed among existing installations, new installations and auctions. Betz et al. (2006, this issue) analyse how the different approaches selected by Member States increase complexity and reduce transparency of the overall system. Much of this complexity arises from industry interests and aims to address distributional concerns. However, the complexity not only complicates participation by industry, but also complicates the role of NGOs and less-informed industrial sectors in controlling the outcome of the political process. Thus the need for harmonization in the methodology used across the Member States has been widely emphasized (e.g. del Rio González, 2006, this issue).

Economic theory and anecdotal evidence also suggest that the methodology chosen for the allowance allocation can directly influence decisions on investment, retrofitting and plant operation.

Fischer (2001) looks at the effects of output-based allocation, Harrison and Radov (2002) provide a policy-oriented description of allocation options, Palmer and Burtraw (2004) focus on distribution effects, Böhringer and Lange (2005) assess macro implications of increased allowance imports from inefficient emission-based allocation, Burtraw et al. (2005) assess the impacts of partial coverage by emissions trading schemes, Entec and NERA (2005) discuss benchmarks, and Matthes et al. (2005) assess distortions in phase I allocation plans, Åhman et al. (2007) argue for longer allocation periods and Bartels and Müsgens (2006) simulate the impact of the German allocation plans on investment decisions. A theoretical framework for the distortions from allocation procedures is provided by Neuhoff et al. (2005) and Sterner and Muller (2006).

This article compares the allocation methodologies envisaged in the different national allocation plans for the period 2008-2012 that have been submitted to the Commission or alternatively which were available in draft format at the end of December 2006.

Taking the power sector as an example, in this study we quantify the differences in free allowance allocation across Member States and across generation technologies.

- For new installations, investment incentives are distorted towards fossil-fuel generation and in many Member States even more towards $\mathrm{CO}_{2}$-intensive fuel types. This reduces the effectiveness of EU ETS in reducing $\mathrm{CO}_{2}$ emissions and compliance costs. Free allocation also represents output subsidies and might thus undermine substitution effects to less $\mathrm{CO}_{2}$-intensive products. 
The free allocation of allowances to new installations, with all its negative implications, is unique to the EU ETS, except for a few 'set asides' in the US $\mathrm{NO}_{\mathrm{x}}$ programme.

- For existing installations, the heterogeneous allocation can distort the merit order choice, incentives for energy efficiency improvements and closure decisions, again detrimental for the cost-efficiency of the EU ETS in reducing $\mathrm{CO}_{2}$ emissions. This effect is even stronger if ex-post adjustment is allowed. This is under legal dispute between Germany and the European Commission and is still demanded by some Member States. The large differences across countries again illustrate that significant reductions in free allowance allocation are not only economically, but also politically, possible.

A reduction in free allowance allocation in the period 2008-2012 could be used both to reduce the overall level of free allocation to the covered sector and also to increase the share of auctions. In its approval of the first 10 national allocation plans, the EU Commission made auctioning the one area of discretionary flexibility within its decision and where the deadline of 31 December 2006 does not apply. 'Without prior acceptance by the Commission', Member States can increase the share of auctioning up to $10 \%$.

Distortions from the free allocation to existing facilities mainly occur because without credible government commitments about future allocation, owners and operators expect that the future allocation will be similar to the current approach. For example, allocation in many Member States factors installation-level emissions data from 2005 into allocation for 2008-2012. Thus, market participants expect future allocations to be similarly 'updated' over time - large emissions today will be rewarded by large volumes of free allocation in the future. This will distort their investment and operational choices (early action problem) and lead to a less cost-efficient outcome with higher costs to society.

A movement towards less distorting allocation methods increases confidence in non-distorting future allocation methods. The use of auctions and the initial use of benchmarks in some sectors and countries represent a promising start. A strong commitment to rapid phasing-out of free allowance allocation post-2012 could avoid most distortions. A thorough assessment of the free allocation under EC Law State Aid criteria could conclude that the continued allocation post-2012 would offer a disproportionate benefit relative to the cost of the environmental regulation (Johnston, 2006). This could provide a credible commitment towards phasing-out free allocation and thus address the early action problem.

This article does not address closure conditions. The expectation of receiving future allowances within the commitment period or in the next commitment period only with the continued availability or operation of a power station creates an incentive to postpone the retirement of power stations or to invest in the retrofit of power plants rather than closing the power station (Spulber, 1985; Neuhoff et al., 2006b). This distortion is only partially compensated for by transfer provisions (Gagelmann, 2006). Åhman and Holmgren (2006) and Betz et al. (2006, this issue) compare such closure and transfer provisions across Member States.

We summarize the information contained in the currently proposed (28 December 2006) national allocation plans for the period 2008-2012 and present it for general scrutiny in an Excel database. ${ }^{1}$ Our first findings regarding the economic effects that might follow from these plans are summarized below. Please note that some national allocation plans still require approval by the Commission, while most of the national allocation plans assessed required some adjustments which are discussed within the Member States. 


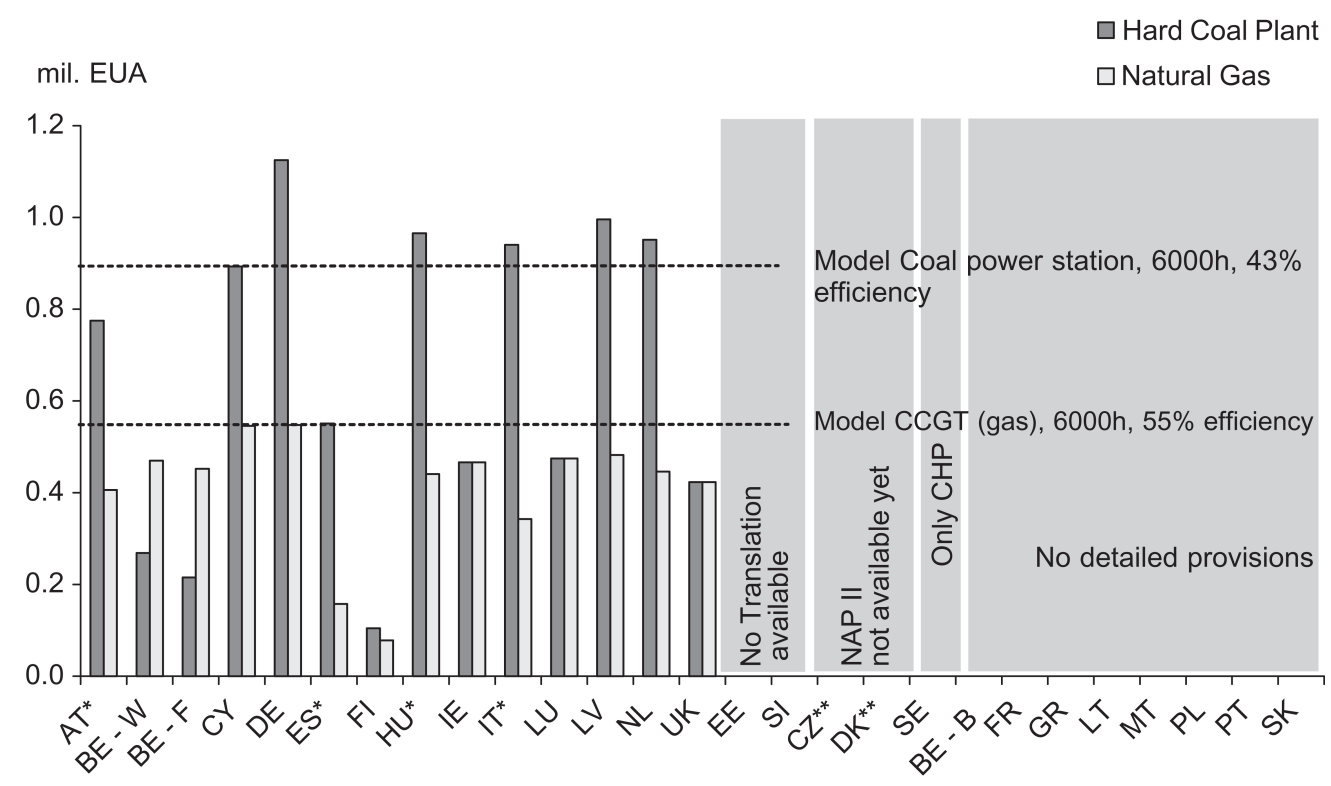

Figure 1. Comparison of new entrant allocation. * Draft NAP, ** NAP not available. In all Figures and Tables the regions of Belgium are identified as BE-F - Flemish, BE-W Walloon, BE-B - Brussels. A different load factor is used for the UK $(5,812 \mathrm{~h}$ for both coal and gas), as indicated in NAP II. In Germany (DE) a standardized load factor of 7,500 h is applied to all power plants.

\section{Quantity of free allocation to installations - using the power sector as an example}

To illustrate the distortions of free allocation to new investment, we calculate the subsidy that it constitutes for new-build coal and gas power stations ${ }^{2}$ across the Member States. ${ }^{3}$ To facilitate the comparison we assumed that a model power station runs for $6,000 \mathrm{~h}$ per year. Figure 1 illustrates that in all Member States, fossil-fuel generators receive high subsidies in terms of free new entrant allocation. In many countries, a new entrant allocation covers the emissions of CCGT gas plants, and in some countries it even covers all the emissions that a coal power station is expected to produce. While it is sometimes argued that new power stations should receive the allowances that they require for covering their emissions, this is not in accordance with economic principles. In liberalized electricity markets, power generators pass the opportunity costs of $\mathrm{CO}_{2}$ allowances into the electricity price (Burtraw et al., 2002; Neuhoff and Keats-Martinez, 2005) and thus do not require any free allocation. This is desirable in order to achieve substitution effects, and is only avoided where electricity price regulation covers just real costs and not opportunity costs (Burtraw et al., 2005).

Any free allocation represents a subsidy - and where only fossil-fuel generation is subsidized, this distorts investment choices in favour of fossil-fuel generation. Where coal receives a higher allocation than gas, the investment choice is, in addition, distorted towards coal. The level of such subsidies under proposed second-phase NAP is so high that the construction of coal power stations is more profitable under the ETS with such distorting allocation decisions than in the absence of the ETS (Åhman and Holmgren, 2006; Matthes et al., 2006; Neuhoff et al., 2006a, this issue). The long-run consequences of these distortions can be significant since, once built, plants will stay on 
the system for many decades, significantly increasing the cost of shifting towards a low-carbon economy in the future (Bartels and Müsgens, 2006; Neuhoff et al., 2006b).

The German National Allocation Plan notified to the Commission not only provided the highest allocation for new coal generation in general, but the draft Allocation Law also contained a provision allowing an even higher free allocation for new lignite-fired installations. In addition, the current NAP guarantees the continuation of free fuel-specific allocation for 14 years. This would undermine investments in low-carbon technologies and has not been accepted by the EU Commission in its decision on the German NAP. Fixing the free allocation beyond the commitment period 20082012 would also reduce the flexibility to evolve climate policy in a national, European and global context in the coming decade and might pre-empt negotiations about future burden sharing between sectors or among European Member States. Since Germany has announced its intention to put climate change on the agenda of its Presidencies of the EU and the G8 in 2007, accepting changes on these long-term provisions would strengthen the German government's credibility for requesting more stringent emission targets from other countries.

Figure 2 illustrates the allocations per Member State to two standard types of existing power stations of $200 \mathrm{MW}$, assuming that they operate on average for $6,000 \mathrm{~h} /$ year. Once again, the large discrepancies between different EU Member States are striking. Also striking is how some countries can still justify large free allocation when others manage to negotiate with their industry a significantly lower level of free allowance allocation.

The high degree of free allocation to the power sector could easily be reduced without reducing power sector profits below pre-ETS levels (Pál and Bartek-Lesi, 2006). As these large demands by individual installations inflate the aggregate national and therefore the EU allowance budgets, such reductions are required in order to achieve a reduction of the EU ETS cap and thus to achieve the Kyoto emission target with sufficient scarcity for a strong price signal.

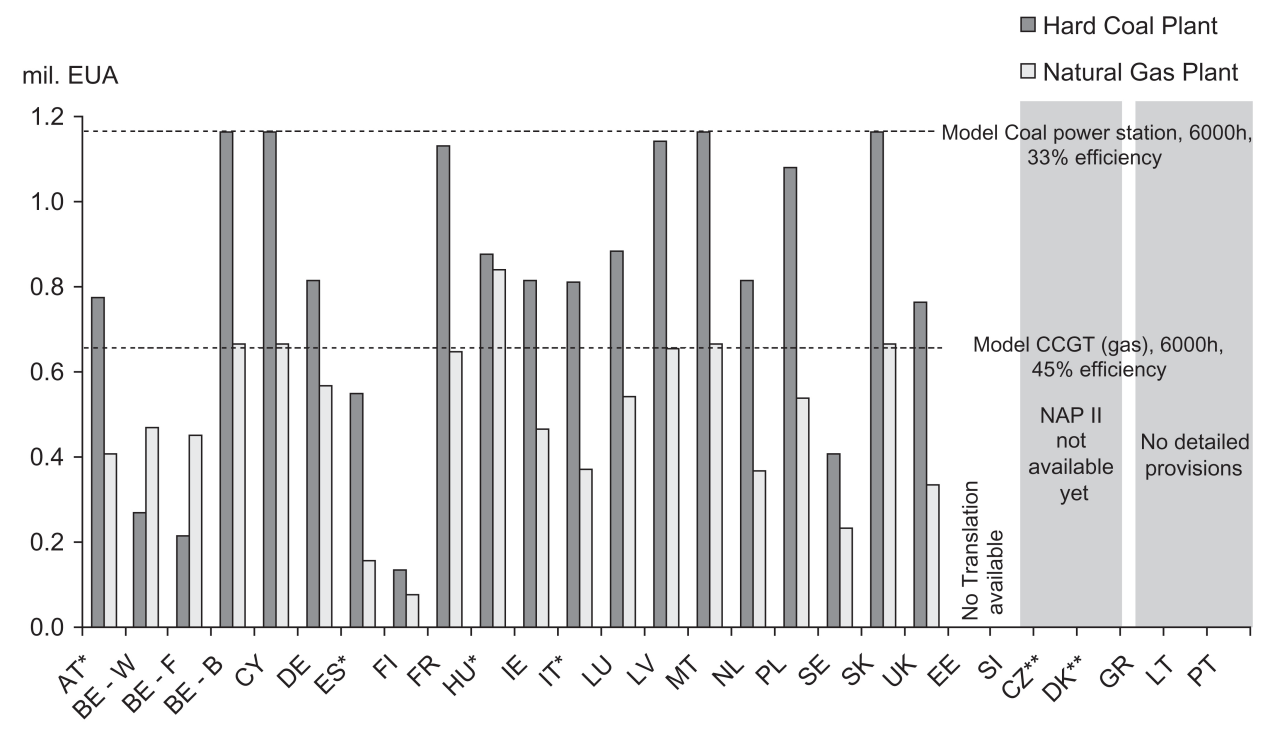

Figure 2. Comparison of allocations to existing facilities. * Draft NAP, ** NAP not available. Different load factors are used for BE-F (3,000 h for coal, $6,300 \mathrm{~h}$ for gas), ES (4,167 $\mathrm{h}$ for coal). $\mathrm{PL}$ - low $\mathrm{SO}_{2}$-emitting installations. $\mathrm{SE}$ - adjustment factor assumed to be equal to 0.35 . 


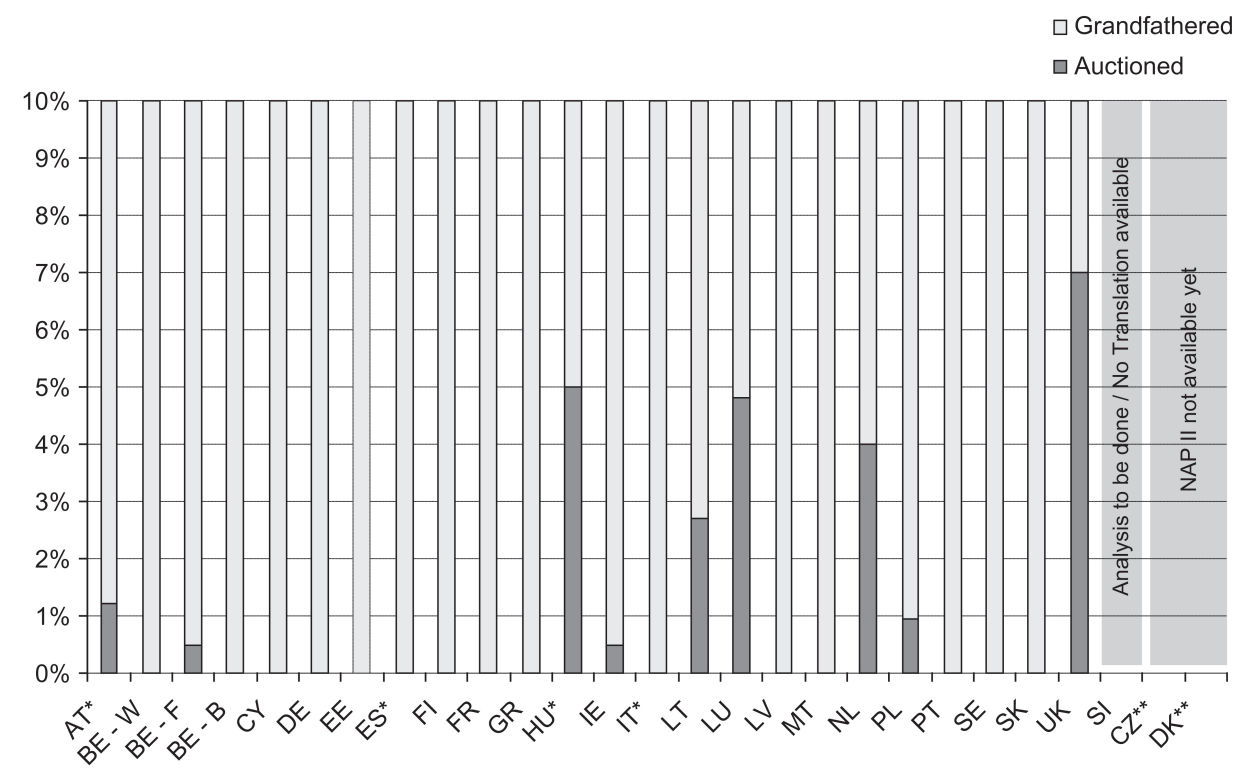

Figure 3. Comparison of the potential to extend the use of auctions between countries. ${ }^{*}$ Draft NAP, ${ }^{* *}$ NAP not available.

\section{The use of auctioning}

The EU Directive allows Member States to auction up to $10 \%$ of the allowances available. Figure 3 illustrates that all Member States can still make more use of this option. Making use of the 10\% auction allowance in this phase would not only reduce distortions from the free allocation, but would also allow all parties involved to become comfortable with allowance auctions. Additionally, a minimum price auction could, by ensuring a price floor, further facilitate investment in lowcarbon technologies (Hepburn et al., 2006). Auction revenues could be recycled to support industrial competitiveness and development and the initial deployment of suitable technologies. Furthermore, auctioning of significant amounts of allowances could support the transparency of the allowances market, especially in the settlement period, and avoid price volatilities resulting from asymmetric risk-hedging strategies between sectors which are short and sectors which hold long positions.

\section{The use of CDM and JI credits}

In the context of the overall Kyoto Protocol implementation framework, the linkage with the international trading scheme is another important dimension. With uncertainty over future demand for JI and CDM credits from Canada, Japan, other Annex I countries, and governments of the EU Member States themselves, some market participants anticipate that the European market could be flooded by these allowances to such an extent that the EU allowance price would plummet. Such uncertainty undermines investment certainty for low-carbon options and also poses obstacles to implementing a price floor using auctions.

Article 30(3) of the EU Directive on Emissions Trading requires that the use of JI and CDM credits is supplementary to domestic action. Figure 4 compares the maximum fraction of total allocation that can be covered by individual installations using JI and CDM credits under the currently proposed NAPs. As all installations can freely trade allowances, the only binding limit is the resulting 


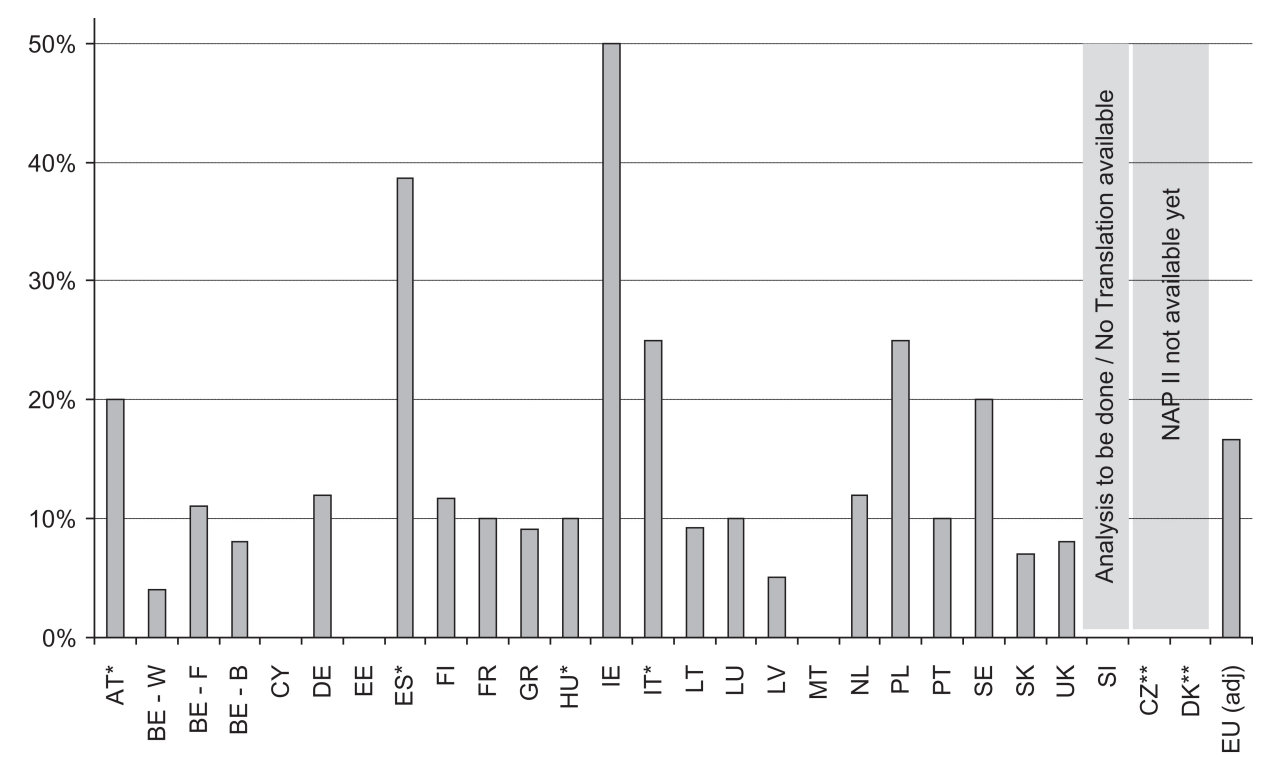

Figure 4. National limits of using JI/CDM credits for EU ETS compliance as a percentage of emissions allocations at installation level ('EU adj' excludes CZ, DK, SI; weighted average for ES). * Draft NAP, ** NAP not available. Limits on the use of Kyoto Credits of $70 \%$ of the overall phase-II allocation for the sector 'Electricity production for public service' and 20\% for the others, at installation level.

overall import volume from JI and CDM credits. Extrapolating from the currently available NAPs for phase II, a maximum of $16.6 \%$ of the emissions of the eligible installations in the EU, or 315.1 $\mathrm{MtCO}_{2}$, may be covered by JI and CDM credits. Whether this upper limit will be reached will depend on prices for EUAs and ERUs or CERs, which in turn depend on demand and supply. The upper limit could for example be reached if Japanese demand, which is estimated to account for about half of total demand for JI and CDM credits (Grubb and Neuhoff, 2006), were to fall.

Article 30(3) requires that the eligible installations across the EU also directly implement measures to reduce emissions by at least the same volume. However, current projections (Neuhoff et al., 2006a, this issue) do not support this hypothesis. Compliance with the Directive would thus require the reduction of the overall budget allocated and/or the volume of JI and CDM credits that can be imported into the EU ETS.

The EU Commission addresses this issue in its decisions on the NAPs. For example, in the Irish NAP the maximum amount of JI and CDM credits that can be used per installation to cover its emissions was declared to be 'inconsistent with Ireland's supplementarity obligations under the Kyoto Protocol and decisions adopted pursuant to the UNFCCC or the Kyoto Protocol, to the extent that it exceeds 21.914\%'(EU Commission, 2006).

\section{The basis for free allocation}

The successful cap-and-trade programmes for $\mathrm{SO}_{2}$ and $\mathrm{NO}_{\mathrm{x}}$ in the USA allocate emission allowances to existing facilities typically based on emissions in a fixed historic base period, and then auction the remaining allowances. Only few US states have set aside allowances of their $\mathrm{NO}_{\mathrm{x}}$ programmes for new sources. Thus, in most cases the free allowance allocation to existing installations constitutes a lump-sum transfer which does not create distortions for the effectiveness of the scheme. 


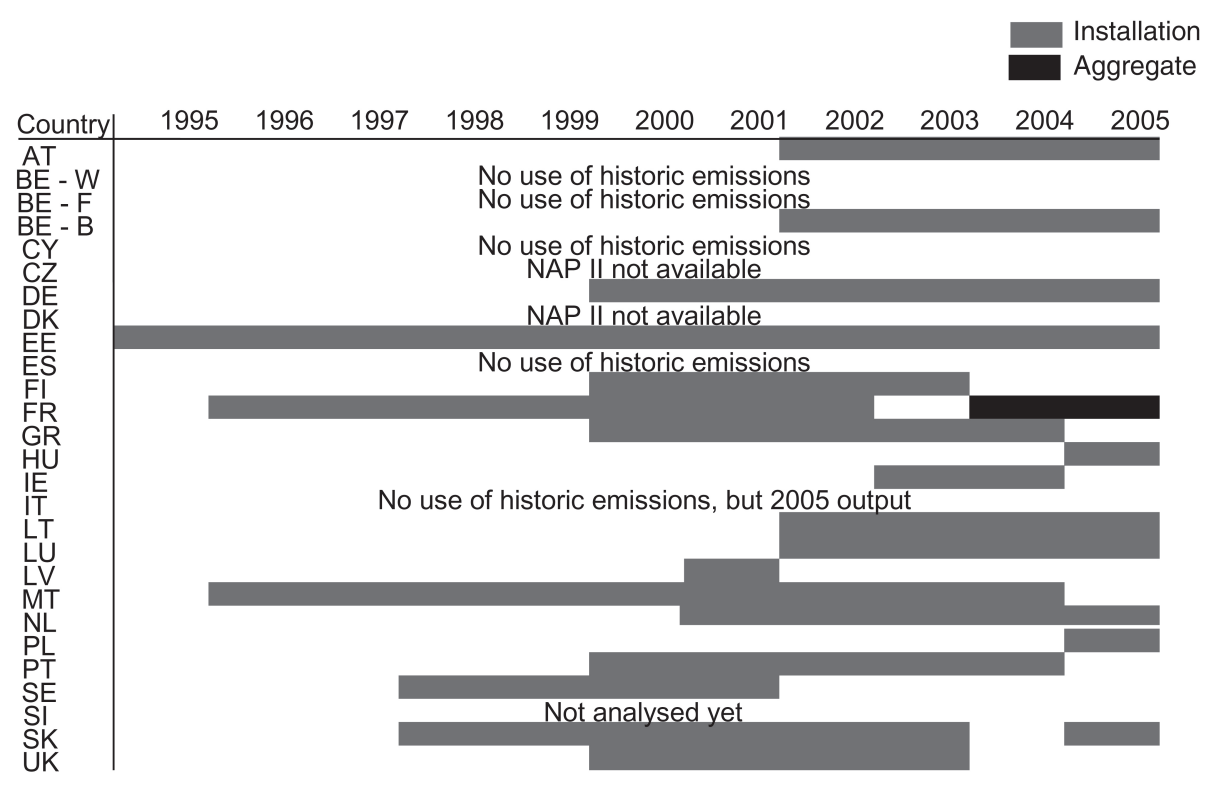

Figure 5. Base period for allowance allocation for the power sector.

In the European context, the limited availability of data, unknown mid- and long-term emissions reduction targets, and distributional considerations (regarding the allocation of allowances valued at around $€ 30$ billion) have prevented such a one-off allocation using one historic base period. Figure 5 shows that the 'historic' base period for allowance allocation for the period 2008-2012 has shifted to take account of the most recent data (including the year 2005) in many Member States.

If allowances are not allocated using a fixed historic base line or an auction, then Table 1 illustrates the different categories that can describe alternative allocation approaches (Grubb and Neuhoff, 2006). In Table 1, X indicates the types of distortions that result from the allocation process. The pyramid shape illustrates the increasing number of distortions that occur as we move down the Table from allocation based on auctions or a one-off allocation using a historic base line, to uniform benchmarks, then to fuel-specific benchmarks, and finally to emission-based allocation. Within each of these categories, in principle, allocation based on installed capacity is preferable to allocation based on projected output, which in turn is preferable to allocation based on historic output. The distortions only apply directly to existing facilities. If, however, investors in new installations expect that they will in the future be covered by similar provisions, then the provisions also result in distortions of investment decisions for new installations.

Following these classifications, we have assessed the performance of the allocation plans of different Member States. In Figure 6 we depict the methodology used to determine the allocation to existing facilities in the power $(\mathrm{P})$ and other $(\mathrm{O})$ sectors.

Distortions from allocation today are largely due to expectations about allocation in the future. For private-sector decision-makers, estimates of future allocation are inevitably based on allocation under the status quo. If emission levels in 2000-2005 are made the basis for the allocations in the period 2008-2012, then plant operators may expect that emissions in the period 2005-2010 will be the basis for the allocation post-2012. This creates a typical early action issue: that is to say, 
Table 1. Effect of allocation methods to existing installations in the power sector

\begin{tabular}{|c|c|c|c|c|c|}
\hline \multirow{2}{*}{$\begin{array}{c}\text { Allowance allocation } \\
\text { method }\end{array}$} & \multirow{2}{*}{ 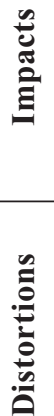 } & \multicolumn{2}{|c|}{$\begin{array}{l}\text { More expenditure on } \\
\text { extending plant life (and } \\
\text { potential minimum-run) } \\
\text { relative to new build }\end{array}$} & $\begin{array}{l}\text { Increase } \\
\text { operation of } \\
\text { (higher) } \\
\text { emitting plants }\end{array}$ & $\begin{array}{l}\text { Less efficiency } \\
\text { improvements }\end{array}$ \\
\hline & & $\begin{array}{l}\text { Discourage } \\
\text { plant closure }\end{array}$ & $\begin{array}{l}\text { Discourage } \\
\text { closure of higher } \\
\text { emitting plants }\end{array}$ & $\begin{array}{l}\mathrm{CO}_{2} \text {-inefficient } \\
\text { fuel choice and } \\
\text { plant operation }\end{array}$ & $\begin{array}{l}\text { Reduce } \\
\text { incentives for } \\
\text { efficiency } \\
\text { improvements }\end{array}$ \\
\hline
\end{tabular}

\begin{tabular}{|c|c|c|c|c|c|}
\hline \multirow{3}{*}{ 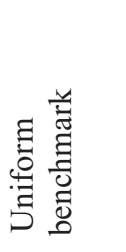 } & \multicolumn{5}{|l|}{ Auction } \\
\hline & Installed capacity & $X$ & & & \\
\hline & Output projection & $X$ & $\mathrm{X}$ & & \\
\hline \multirow{4}{*}{ 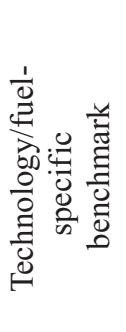 } & Historic output & $\mathrm{X}$ & $\mathrm{X}$ & $(X)^{\mathrm{a}}$ & \\
\hline & Installed capacity & $\mathrm{X}$ & $\mathrm{X}$ & & \\
\hline & Output projection & $\mathrm{X}$ & $\mathrm{X}$ & & \\
\hline & Historic output & $\mathrm{X}$ & $\mathrm{X}$ & $X$ & \\
\hline \multirow{2}{*}{ 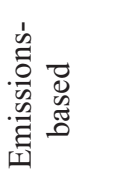 } & Emissions projection & $\mathrm{X}$ & $\mathrm{X}$ & & $\mathrm{X}$ \\
\hline & Historic emissions & $\mathrm{X}$ & $\mathrm{X}$ & $\mathrm{X}$ & $\mathrm{X}$ \\
\hline
\end{tabular}

a To avoid distortions between generation technologies, non-fossil-fuel stations would also have to receive free allowances. This would avoid internalization of $\mathrm{CO}_{2}$ costs in the electricity price, and thus distort choices of input factors and consumption for electricity consumers.

allocation undermines the incentives to invest in emission reductions because such investment may be 'punished' during future allowance allocation. As allocation plans for phase II continue to allocate most allowances to existing facilities based on historic emissions, the early action problem remains to be addressed. Some countries experiment with benchmark approaches - and thus could possibly increase the confidence of private-sector investors that future allowance allocation methodology will improve in terms of economic efficiency and environmental effectiveness.

Figure 7 provides the same analysis for the allocation methodology to new entrants, again separately for the power sector $(\mathrm{P})$ and other sectors $(\mathrm{O})$. It illustrates the variety of approaches selected by different Member States. The big challenge, again, comes from the distortions that follow from private-sector expectations regarding the allocation methodologies in subsequent periods. Thus the assessment of the allocation for the existing installations also carries significance for investment decisions for new facilities. 


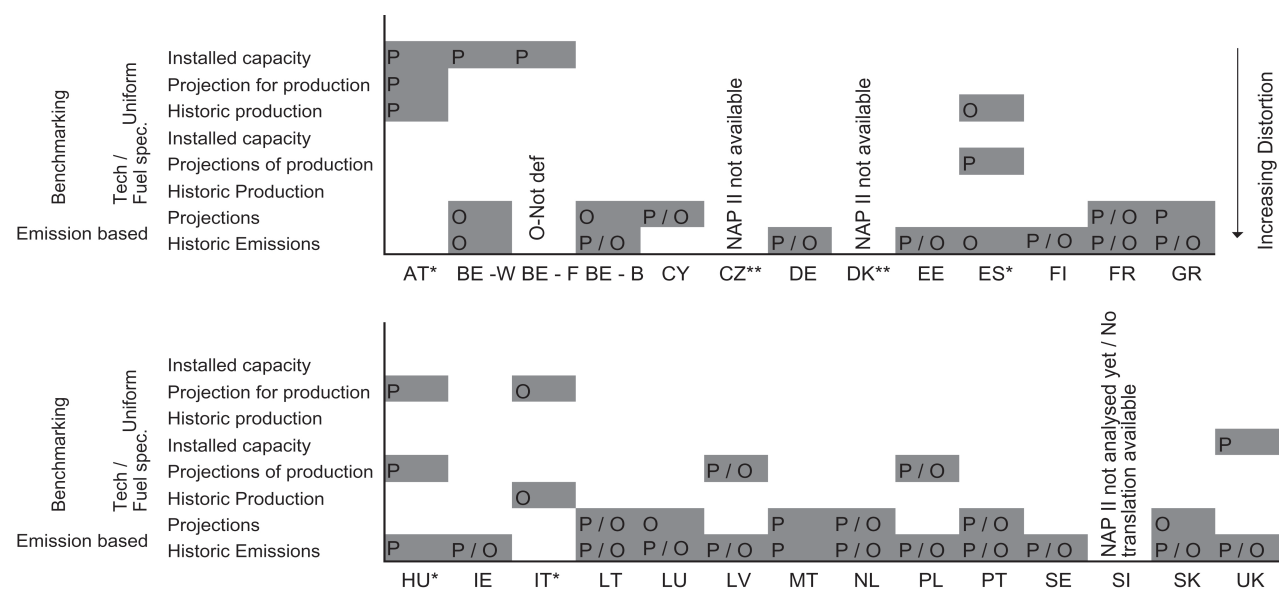

Figure 6. Pyramid of distortions applied to existing installations, power $(\mathrm{P})$ and others $(\mathrm{O})$.

\section{Conclusions}

We have quantified the volume of free allowances that different national allocation plans envisage to allocate to the power sector. This varies widely across Member States and technologies and can create strong distortions of investment decisions. The level of free allocation seems rather high, given that in most EU countries the electricity market is liberalized and electricity generators are therefore in a position to pass through the opportunity costs of $\mathrm{CO}_{2}$ allowances. Thus, a significant reduction in free allowance allocation to the power sector seems viable for phase II of the NAPs. As the aggregate demand of individual installations inflates national, and therefore EU, allowance budgets, any such reduction could facilitate a reduction in the EU ETS cap as proposed by the EU Commission in its decision on the first 10 NAPs announced on 29 November 2006. This in turn can ensure sufficient scarcity of $\mathrm{CO}_{2}$ allowances and a viable emissions market that drives low-carbon investment decisions.
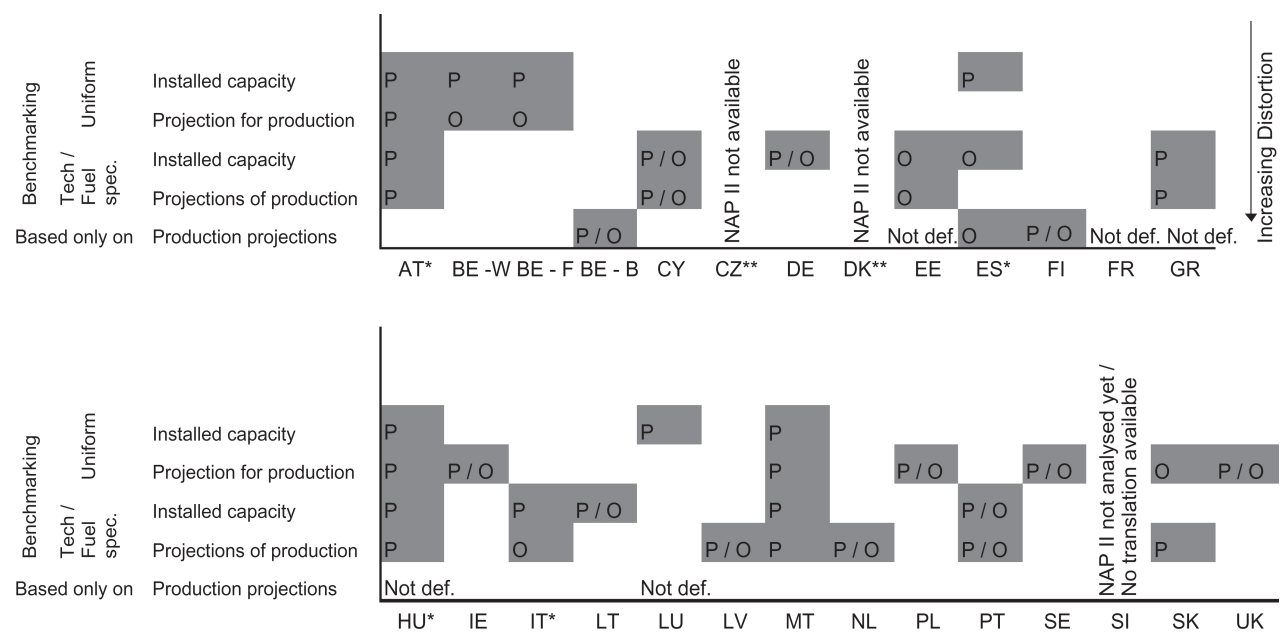

Figure 7. Pyramid of distortions applied to new installations, power (P), others (O). 
A reduction in free allowance allocation, mainly to the power sector, could in addition allow for an increased use of the auctioning of $\mathrm{CO}_{2}$ allowances. Auction volumes vary significantly across Member States. In all Member States, the potential for an increase to $10 \%$ envisaged by the Directive remains. The Commission made auctioning the one area of discretionary flexibility within its decision on the first 10 NAPs, 'without prior acceptance by the Commission', and even after the deadline of 31 December 2006. If a tighter cap, stringent limits on CDM and JI inflows, and 10\% auctions were implemented, then a price floor in the auction - agreed between EU Member States could also establish a price floor for EU allowances and thus facilitate low-carbon investments.

A comparison of the volume of CDM and JI credits that individual installations are allowed to use to cover their $\mathrm{CO}_{2}$ emissions shows large discrepancies between Member States. A more stringent approach seems required in order to satisfy the supplementarity criteria of the Directive and also to avoid too much exposure of the EU ETS market to the uncertainties regarding Japanese and Canadian demands for JI and CDM credits. The Commission decided to disallow the higher limits envisaged in the Irish NAP.

Most allowances are still allocated relative to historic emissions. If the private sector takes this as an indicator for future allowance allocation, then we may face a serious early action problem. Some Member States have started to explore different benchmarking approaches, mainly for the power sector. This has the potential to reduce, but not eliminate, the economic distortions from free allowance allocation. Thus, to ensure the effectiveness of EU ETS in the coming years, it is important to provide credible evidence to the private sector that free allowance allocation will be drastically reduced post-2012. By disallowing the German provision to commit to free allowance allocation post-2012, the Commission has ensured that we retain the flexibility for such changes.

Finally, the EU Directive on Emissions Trading requires that Member States notify their national allocation plans to the Commission to be assessed in relation to State Aid criteria. There are some concerns that the excessive allocation to sectors that both pass on opportunity costs and receive free allowance allocation cannot be aligned with EC Law State Aid criteria (Johnston, 2006). One solution might be to treat the resulting benefits as a transitional payment to compensate for the transition costs of the environmental regulation. This would, however, require a strong commitment to phasing-out free allocation post-2012 - and would thus also address the early action problem.

\section{Acknowledgements}

This article was sponsored by Climate Strategies (www.climate-strategies.org), with the Carbon Trust as lead investor. The opinions expressed in this article are those of the authors and do not express the views of the Carbon Trust.

Financial support from the UK Research Council, Project TSEC, is gratefully acknowledged.

\section{Notes}

1 The database, which can be found at http://www.econ.cam.ac.uk/research/tsec/euets/, covers volume of the allocation, verified and projected emissions, allocation methodologies for power and non-power sectors, auctioning, general features, and evaluation of the allocation that a standard power plant would receive in each Member State according to the proposed rules.

2 We assume a $200 \mathrm{MW}$ coal power station and combined cycle gas turbine with efficiencies of 33\% (existing coal), $45 \%$ (existing CCGT gas), 43\% (new coal) and 55\% (existing CCGT gas).

3 BE-W Belgium Walloon, CY Cyprus, DE Germany, ES Spain, FI Finland, HU Hungary, IE Ireland, IT Italy, LV Latvia, NL Netherlands, UK, BE-F Belgium Flemish, EE Estonia, LU Luxembourg, SI Slovenia, AT Austria, CZ Czech Republic, DK Denmark, SE Sweden, BE-B Belgium Brussels, FR France, GR Greece, LT Lithuania, MT Malta, PL Poland, PT Portugal, SK Slovakia. 


\section{References}

Åhman, M., Holmgren, K., 2006. Harmonising New Entrant Allocation in the Nordic Energy Sectors: Current Principles and Options for EU ETS Phase II. IVL Swedish Environmental Research Institute, Stockholm, Sweden.

Åhman, M., Burtraw, D., Kruger, J., Zetterberg, L., 2007. A Ten-Year Rule to guide the allocation of EU emission allowances. Energy Policy 35(3), 1718-1730.

Bartels, M., Müsgens, F., 2006. Do technology specific $\mathrm{CO}_{2}$ allocations distort investments? In: Securing Energy in Insecure Times. International Association of Energy Economics, Potsdam, Germany.

Betz, R., Rogge, K., Schleich, J. 2006. EU emissions trading: an early analysis of national allocation plans for 2008-2012. Climate Policy 6(4), 361-394.

Böhringer, C., Lange, A., 2005. Mission impossible!? On the harmonization of national allocation plans under the EU Emissions Trading Directive. Downloadable Appendix: CGE model description. Journal of Regulatory Economics 27(1). 81-94.

Burtraw, D., Palmer, K., Bharvirkar, R., Paul, A., 2002. The effect on asset values of the allocation of carbon dioxide emissions allowance. Electricity Journal 15(5), 51-62.

Burtraw, D., Palmer, K., Kahn, D., 2005. Allocation of $\mathrm{CO}_{2}$ Emissions Allowances in the Regional Greenhouse Gas Cap-andTrade Program. RFF Discussion Paper 05-25. Resources for the Future, Washington, DC.

del Rio González, P., 2006. Harmonization versus decentralization in the EU ETS: an economic analysis. Climate Policy 6(4), 457-475. Entec and NERA (2005). EU Emissions Trading Scheme Benchmark Research for Phase II. Final Report. DTI.

EU Commission, 2006. Decision on Irish NAP, 29 November [available at http://ec.europa.eu/environment/climat/ 2nd_phase_ep.htm].

Fischer, C., 2001. Rebating Environmental Policy Revenues: Output-Based Allocations and Tradable Performance Standards. RFF Discussion Paper 01-22. Resources for the Future, Washington, DC.

Gagelmann, F., 2006. Innovation Effects of Tradable Emission Allowance Schemes: The Treatment of New Entrants and Shutdowns. UFZ (Centre For Environmental Research), Department of Economics, Discussion Paper 4/2006.

Grubb, M., Neuhoff, K., 2006. Allocation and competitiveness in the EU emissions trading scheme: policy overview. Climate Policy 6(1), 7-30.

Harrison, D.J., Radov, D.B., 2002. Evaluation of Alternative Initial Allocation Mechanisms in a European Union Greenhouse Gas Emissions Allowance Trading Schemes. NERA Report to DG Environment, European Commission, NERA.

Hepburn, C., Grubb, M., Neuhoff, K., Matthes, F., Tse, M., 2006. Auctioning of EU ETS phase II allowances: how and why? Climate Policy 6(1), 137-160.

Johnston, A., 2006. Free allocation of allowances under the EU emissions trading scheme: legal issues. Climate Policy 6(1), 115-136.

Matthes, F., Graichen, V., Harthan, R.O., Repenning, J., 2006. Auswirkung verschiedener Allokationsregeln auf Investitionen im Strommarkt, www.oeko.de.

Matthes, F., Graichen, V., Repenning, J., Doble, C., Macadam, J., Taylor, S., Zanoni, D., Chodor, M., 2005. The Environmental Effectiveness and Economic Efficiency of the European Union Emissions Trading Scheme: Structural Aspects of Allocation. WWF, Öko Institute.

Neuhoff, K., Keats-Martinez, K., 2005. Allocation of carbon emission certificates in the power sector: how generators profit from grandfathered rights. Climate Policy 5(1), 61-78.

Neuhoff, K., Grubb, M., Keats, K., 2005. Impact of the Allowance Allocation on Prices and Efficiency. Electricity Policy Research Group, Judge Institute of Management, University of Cambridge, Cambridge, UK.

Neuhoff, K., Ferrario, F., Grubb, M., Gabel, E., Keats, K., 2006a. Emission projections 2008-2012 versus national allocation plans II. Climate Policy 6(4), 395-410.

Neuhoff, K., Keats Martinez, K., Sato, M., 2006b. Allocation, incentives and distortions: the impact of EU ETS emissions allowance allocations to the electricity sector. Climate Policy 6(1), 73-91.

Pál, G., Bartek-Lesi, M., 2006. The Polluter Profits Principle: A Note on the Grandfathering of $\mathrm{CO}_{2}$ Emissions Rights in LaxCap Trading Regimes. REKK (Regional Centre for Energy Policy Research) Working Paper 2006-1.

Palmer, K., Burtraw, D., 2004. Distribution and Efficiency Consequences of Different Approaches to Allocating Tradable Emission Allowances for Sulfur Dioxide, Nitrogen Oxides and Mercury. RFF Discussion Paper. Resources for the Future, Washington, DC.

Spulber, D.F., 1985. Effluent regulation and long-run optimality. Journal of Environmental Economics and Management 12(2), $103-116$.

Sterner, T., Muller, A., 2006. Output and Abatement Effects of Allocation Readjustment in Permit Trade. RFF Discussion Paper 06-49. Resources for the Future, Washington, DC. 